Notas Epidemiológicas

\title{
SURTO DE TOXINFECÇÃO ALIMENTAR POR SALMONELLA BREDENEY
}

\author{
Mariza Landgraf* \\ José Angelo Gonçalves** \\ Deise Pasetto Falcão****
}

Um surto de toxinfecçăo alimentar por S. bredeney ocorreu na cidade de Araraquara em 1983. A partir da madrugada do dia 7 de abril até o final da tarde desse mesmo dia, 561 operários de uma indústria apresentaram problemas gastrintestinais. A refeição suspeita de ser a causadora do surto foi servida para 922 pessoas, no refeitório da indústria, durante o almoço do dia anterior. Tal refeição constava de carne assada com molho, lingüiça assada, salada, arroz, feijão, pão, abacaxi, bem como água e leite. A sintomatologia clínica e a ocorrência de febre sugeriram um quadro de gastrenterite por Salmonella.

Os sintomas predominantes foram diarréia, dores abdominais, vômito e febre (389̣C em média). 0 período da doença foi, em média, 3 dias, quando a maioria dos pacientes esteve incapacitada para o trabalho. Aproximadamente $7,5 \%$ dos pacientes precisaram ser hospitalizados, mas não ocorreu qualquer 6bito.

O laboratório de Microbiologia da Faculdade de Ciências Farmacêuticas da Universidade Estadual Júlio de Mesquita Filho (UNESP) foi solicitado a realizar coproculturas e análise microbiológica de alimentos servidos durante a refeição, provavelmente relacionada ao surto.
Realizaram-se 17 coproculturas e análise de porçбes de alguns alimentos servidos na refeição suspeita: carne assada com molho, maionese, bacon (que havia sido cozido no feijáo), leite, pimenta do reino, lingüiça crua pois a assada havia sido toda consumida), e de água potável e água do banho-maria utilizado no aquecimento dos alimentos. Porçoes dos demais alimentos náo se encontravam disponíveis.

As coproculturas foram realizadas segundo as técnicas usuais ${ }^{1}$, empregando no enriquecimento os caldos de tetrationato de Kauffmann e selenito. As colonias suspeitas relativas a 17 coproculturas foram identificadas bioquímica e sorologicamente através de soros polivalentes $\mathrm{O}$ e $\mathrm{H}$ anti-salmonela, quando se confirmou a presença de Salmonella sp. Nos meios seletivos diferenciadores isolou-se Salmonella praticamente em cultura pura, o mesmo ocorrendo após a semeadura direta. Todas as amostras de Salmonella sp., apos tipagem, foram identificadas como S. bredeney.

As amostras de alimentos, água e especiaria foram cultivadas segundo as técnicas preconizadas, pela American Public Health Association $^{2}$, sempre utilizando como enriquecimento o caldo de tetraionato de Kauf-

- Do Departamento de Alimentos e Nutrição da Faculdade de Ciências Farmacêuticas da Universidade Estadual Júlio de Mesquita Filho (UNESP) - "Campus" de Araraquara - Caixa Postal 131 - 14800 Araraquara, SP - Brasil.

* Médico do trabalho. Araraquara, SP - Brasil.

* Do Departamento de Ciências Bio-Clínicas da Faculdade de Ciéncias Farmacêuticas da Universidade Estadual Júlio de Mesquita Filho (UNESP) - "Campus" de Araraquara - 14800 - Araraquara, SP Brasil. 
LANDGRAF, M. et al. Surto de toxinfeç̧āo alimentar por Salmonella bredeney. Rev. Saude publ, S. Paulo, 19:92-3, 1985

fmann e caldo selenito cistina. As culturas foram realizadas em duplicata e em alguns casos em triplicata. Não foi isolada $S$. bredeney a partir de qualquer das amostras examinadas. Da lingüiça crua isolou-se Salmonella 4, 5, 12:i:-monofásica, diferente portanto do sorotipo isolado das fezes dos doentes.

Por motivos alheios à nossa vontade não foi possível fazer um levantamento dos alimentos ingeridos por todas as 922 pessoas que tomaram a refeiçăo, provavelmente rela- cionada ao surto, mas apenas com parte dos doentes. Assim, não foi possível realizar o traçado epidemiológico do surto.

Deve ser ressaltado que as 17 coproculturas foram positivas para Salmonella bredeney e que para todos os pacientes a fonte de infecção foi, provavelmente, a mesma, ou seja, o restaurante da indústria. Assim, pode ser considerado então que o veículo do agente etiológico envolvido no surto deve ter sido um ou mais alimentos servidos.

\section{REFERÊNCIAS BIBLIOGRÁFICAS}

1. EDWARDS, P.R. \& EWING, W.H Identifica. tion of Enterobacteriaceae. $3^{\text {td }}$ ed. Minneg. polis, Burgess Publishing, 1972.

2. POELMA. P.L. \& SILLIKER, J.H. Salmonel la. In: Speck. M.L., ed. Compendium of methods for the microblological examina- tion of foods Washington, D.C., American Public Health Association, 1976. p. 301. 28.

Recebido para publicacio em 31/07/1984. Reapresentado em 07/01/1985.

Aprovado para publicafio em 10/01/1985. 